\title{
INNOVACIÓN EN MUSEOS: MUSEO Y COMUNIDAD EN LA OFERTA AL TURISMO CULTURAL
}

\author{
Georgina DeCarli
}

Fundación ILAM*

\section{Resumen:}

El presente artículo aborda la temática del museo (local o regional) y su incidencia en una oferta de calidad para el turismo cultural, por medio del cual los potenciales visitantes sean atraídos por servicios y productos verdaderamente representativos de la cultura local, y puedan interactuar directamente con sus creadores. Para lograrlo la estrategia principal del museo consiste en establecer una nueva relación con la comunidad para involucrarla como aliada y como socia en la propuesta de una oferta diversificada que se destaca por su singularidad y autenticidad. Esto posibilita que los miembros de la comunidad que poseen los conocimientos tradicionales se beneficien utilizando en forma responsable sus propios recursos patrimoniales para mejorar su calidad de vida, $y$ al museo obtener nuevos ingresos y dinamizar su oferta cultural. Se presenta como caso de estudio el Museo de Cultura Popular en Costa Rica.

Palabras clave: museo, comunidad, recursos patrimoniales, sostenibilidad, calidad.

\section{Resumo: Innovación en museos: museo e comunidade na oferta de turismo cultural}

O presente artigo aborda a temática do museo (local ou rexional) e a súa incidencia nunha oferta de calidade para o turismo cultural, por medio da cal os potenciais visitantes sexan atraídos por servizos e produtos verdadeiramente representativos da cultura local e lles ofreza interactuar directamente cos seus creadores. Para logralo, a estratexia principal do museo consistiría en establecer unha nova relación coa comunidade no seo de que se insire para involucrala como aliada e como socia na proposta dunha oferta diversificada que destacase pola súa singularidade e autenticidade. Isto posibilitaría, por unha banda, que os membros da comunidade que posúen os coñecementos tradicionais se beneficiasen empregando de forma responsable os seus propios recursos patrimoniais para mellorar a súa calidade de vida, e, pola outra, que o museo obtivese novos ingresos e dinamizase a súa oferta cultural. Preséntase como caso de estudo o Museo de Cultura Popular en Costa Rica.

Palabras clave: museo, comunidade, recursos patrimoniais, sustentabilidade, calidade.

\begin{abstract}
Innovation in museums: Museums and communities in the cultural tourism offer.
This article addresses the subject of museums (local or regional) and their impact on a quality offer for cultural tourism, whereby potential visitors are attracted by services and products that are truly representative of the local culture, and may interact directly with the creators. In order to do so, the main strategy of museums consists of establishing a new relationship with the community, in order to get it involved as an ally and a partner in proposing a diversified offer that stands out for its singularity and authenticity. This makes it possible for those members of the
\end{abstract}

*ilam@ilam.org 
community who have traditional knowledge to benefit, by responsibly using their own heritage resources to improve their quality of life, and for museums to obtain new revenue and revitalise their cultural offer. As a case study, we analyse the Museum of Popular Culture in Costa Rica.

Key words: museum, community, heritage resources, sustainability, quality.

La existencia de nuevos escenarios está alterando la tradicional forma de gestión de los museos, abriendo a su vez nuevas posibilidades y creando nuevas necesidades. La demanda del turismo cultural, internacional y nacional, posibilita al museo convertirse en una "puerta de entrada" a la diversidad natural y cultural del territorio que éste comprende, ampliando y diversificando su oferta más allá de los muros del museo; y esto es justamente lo que exige el turista visitante.

El viajero actual quiere vivir una experiencia diferente. La experiencia de lo auténtico en la naturaleza, la cultura, la gente o una combinación de éstas, su desarrollo se lleva a cabo preferiblemente en áreas con pequeñas poblaciones, entornos rurales y atractivas áreas naturales.

"Los turistas se dirigen preferentemente a museos representativos de la historia, la cultura y las tradiciones del país anfitrión con el afán de conocer lo que les resulta mas novedoso y particular; tal es el caso de las instituciones de carácter regional o local, donde es más directa la relación con las comunidades" (ICOM: 2000). Sin embargo la oferta de estos museos deja mucho que desear ante las expectativas del turista interesado en conocer la cultura local e interactuar con sus pobladores.

\section{LA OFERTA CULTURAL EN LAS COMUNIDADES}

Las causas de que en América Latina y el Caribe no se evidencie un turismo cultural de calidad en las comunidades, a pesar del riquísimo acervo y tradiciones que poseen, se debe a tres circunstancias concomitantes:

- La primera, es la falta de información sobre los recursos patrimoniales existentes y sus niveles de accesibilidad. Los recursos existentes son muchos pero pocos de ellos cuentan con infraestructuras adecuadas para ser visitados y disfrutados.

- La segunda, es la escasa existencia de servicios y/o productos culturales verdaderamente representativos de la cultura y tradición local; es decir que hayan sido resultado de un proceso de investigación y debidamente contextualizados permitiendo una presentación novedosa y accesible para el turista, pero que responden a la tradición cultural del lugar.

- La tercera, estrechamente relacionada con la anterior, es que cuando estos servicios y/o productos existen, éstos son escasamente conocidos ya que tienen una deficiente promoción y mercadeo.

Al no existir la posibilidad de contar con información elemental sobre los recursos existentes, así como de las posibles ofertas que se generan localmente, hace que los potenciales oferentes de servicios (tour operadores, agencias, etc.) no puedan utilizar estos recursos para integrarlos en una propuesta atractiva para el turista, como podría ser 
un recorrido cultural de un día, integrando la visita de recursos patrimoniales históricos y naturales, así como el disfrute artístico y gastronómico.

Esta realidad tiene como consecuencia directa que los ingresos que pudieran provenir del turismo cultural no tengan incidencia en el desarrollo local.

En Latinoamérica, las comunidades y específicamente sus sectores menos favorecidos, no están posibilitados para utilizar su patrimonio cultural y natural en la generación de beneficios propios y por lo tanto como factor de desarrollo. A pesar de ser estas comunidades herederas directas de los recursos naturales y bienes culturales que les han sido transmitidos de generación en generación, no pueden hacer uso de sus propios recursos patrimoniales porque sus condiciones socio-culturales y educativas les impiden apropiarse de éstos en términos responsables y sostenibles, convirtiéndose muchas veces en destructores de estos invaluables e irremplazables recursos.

Para que las comunidades puedan ejercer su derecho de beneficiarse de sus recursos patrimoniales, siendo parte de la oferta de servicios y/o productos al turismo cultural, se requiere de un proceso de facilitación de acciones de concientización, capacitación, investigación, organización, mercadeo y difusión, entre otras, que posibiliten que las mismas comunidades puedan llevar a cabo un usufructo responsable de estos recursos.

Los museos son justamente las instituciones indicadas para acompañar a las comunidades en el desarrollo de estos procesos. ¿Por qué? Podríamos decir, porque están en el lugar preciso, en medio de las comunidades y porque su misión e incesante labor es la protección de los bienes patrimoniales bajo su custodia y consecuentemente su investigación, difusión y la implementación de acciones de educación no-formal para su conocimiento, valoración y disfrute.

Pero la razón principal es porque hoy en día, los museos reconocen que su responsabilidad prioritaria es la preservación del patrimonio integral y que esto sólo será posible involucrando a los miembros de la comunidad en acciones de preservación conjunta, acompañándolos en un proceso de apropiación y capacitación que les posibilite ejercer su derecho al uso responsable de sus recursos patrimoniales debido a que (DeCarli, 2007):

- Todo patrimonio es local: todo patrimonio se genera localmente, y es producido en un espacio y en un tiempo histórico determinado; desde luego los aportes culturales de los inmigrantes están considerados como parte de este mismo proceso histórico. El paso del tiempo y el consenso social permite que este patrimonio local pueda llegar a ser asumido como patrimonio regional, nacional o mundial.

- El patrimonio funciona y se manifiesta en forma integral: entendemos este patrimonio integral como "el conjunto de bienes culturales y naturales, tangibles e intangibles, generados localmente y que una generación hereda / transmite a la siguiente con el propósito de preservar, continuar y acrecentar dicha herencia."

- La comunidad es la responsable en la preservación de su patrimonio: al ser un fenómeno fundamentalmente local, todo patrimonio (cultural, natural, tangible o intangible) depende para su transmisión y preservación, en primera instancia, de la comunidad en donde tuvo origen, o la cual estuvo de alguna manera involucrada en su desarrollo. 
Por ello decimos que los museos pueden, en alianza con su comunidad, llevar a cabo la oferta de servicios y productos culturales de calidad, resultado de una actividad conjunta, la cual produciría en el turista un mayor impacto y la vivencia de significativas experiencias, posibilitándole también la comprensión de la comunidad que visita y de los recursos patrimoniales que esta preserva, fomentando de esta manera el respeto a la diversidad cultural.

\section{LA PROPUESTA DE LA NUEVA MUSEOLOGÍA COMO REFERENTE TEÓRICO-METODOLÓGICO}

En los años setenta dio inicio una corriente teórico-metodológica como propuesta de museólogos conscientes de la necesidad de renovar o inclusive superar la institución museo. Estos planteaban la necesidad de generar diversas experiencias donde el museo integrara como dinámica propia la investigación, preservación y comunicación del patrimonio natural y cultural con las comunidades, fortaleciendo así su identidad cultural.

De acuerdo con Lacouture (1994) el «museo» que propone la Nueva Museología se define en los siguientes términos:

Conceptos del Nuevo Museo:

- Confronta al Hombre con: elementos naturales / seres vivos / objetos / monumentos

- Transforma al museo tradicional: de un edificio hace una región / de una colección hace un patrimonio regional / de un público hace una comunidad participativa.

- Trata de recuperar: la identidad natural y cultural de los espacios regionales y nacionales a través de las imágenes y memorias colectivas.

Objetivos del Nuevo Museo:

- Fomentar la identidad y la conciencia patrimonial de las comunidades que conforman el nuevo museo, mediante su acción conjunta en el rescate, conservación, mejor uso y difusión de su patrimonio natural y cultural, en un verdadero acto pedagógico para el eco-desarrollo.

- Fomentar el conocimiento de ambos patrimonios, mediante el turismo cultural y social, tanto regional interno como nacional o ajeno a la región.

- Confrontar al visitante con los objetos culturales y con su realidad natural, en el ámbito y contexto originales, prefiriéndolos a la concentración patrimonial limitante del museo tradicional.

- Coadyuvar al mejor aprovechamiento del territorio, de los recursos culturales y de los recreativos.

A partir de esta propuesta se dan dos procesos paralelos, por un lado la creación de nuevos museos a la luz de estos criterios (eco-museos, museos comunitarios, etc.) y por otro, la revisión de los museos ya existentes, a fin de diagnosticar su funcionamiento y decidir cuáles cambios se pueden lograr, cuáles implicaciones tendrían y qué resultados se esperarían. 
Gráfico 1. Representación de la propuesta de la Nueva Museología

PROPUESTA DE LA NUEVA MUSEOLOGÍA (NM)

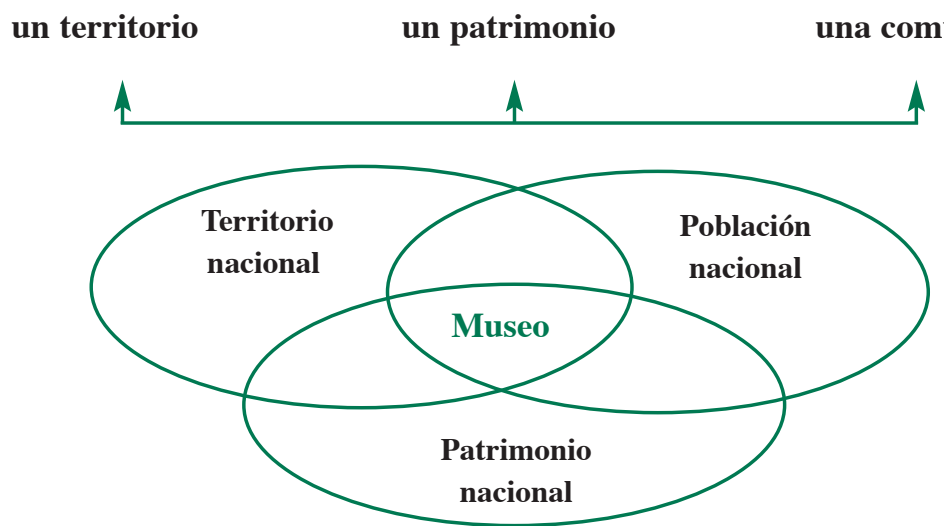

Nuestra propuesta actual se enmarca en este segundo proceso, en la medida que consideramos que todos los museos existentes, principalmente los locales y regionales tienen -si no las condiciones óptimas - sí las características necesarias para emprender un proceso de investigación, capacitación y reforzamientos de habilidades con los miembros de las comunidades para la implementación conjunta de productos y servicios al público visitante y al turismo cultural.

\section{COMPARTIENDO INFORMACIÓN SOBRE LOS RECURSOS PATRIMO- NIALES}

Para que el museo pueda implementar y desarrollar eficazmente las diversas actividades que se propone realizar para su oferta diversificada y novedosa al público y al turista, se deben establecer estrategias de detección de información, recolección de datos y sistema de registro, idealmente, un Inventario de Bienes Culturales (DeCarli y Tsagaraki, 2006) integrado por:

- los objetos de la(s) colección(es) que posee el museo, sus antecedentes históricos y su contexto patrimonial,

- las actividades / oficios, conocimientos y creencias asociadas con su uso y las técnicas de su elaboración, los productores o personas que poseen los conocimientos tradicionales y sus vínculos con la comunidad,

- las prácticas culturales de la comunidad, entendidas éstas como el conjunto de costumbres, actitudes, creencias y valores,

- los recursos patrimoniales culturales y naturales que se encuentran en la región. 
La obtención de información, independientemente de la capacidad de investigación interna que posea el museo, debe proceder de diversas fuentes y revertirse posteriormente a los posibles usuarios. Hay dos fuentes principales: la proveniente de las alianzas con otras instituciones (como universidades) y la proveniente de la investigación participativa con miembros de la comunidad.

Es deseable que el Inventario sea un instrumento que posibilite ser utilizado como fuente de información por los diferentes sectores o "actores sociales" de la localidad para diversos propósitos que incidan en su nivel y calidad de vida. De este modo su múltiple acceso coadyuvará más efectivamente a la preservación de los bienes culturales del patrimonio local, ya que solamente se puede proteger aquello que se conoce y es significativo para uno mismo y para su entorno.

Por lo tanto, un Inventario de Bienes Culturales del patrimonio de una localidad debe ser suficientemente flexible para integrar:

I Diversos patrimonios: al permitir relacionar, por medio de categorías comunes, los diversos patrimonios, entre los cuales se incluyen los siguientes:

El Patrimonio Cultural es el conjunto de bienes tangibles e intangibles, que constituyen la herencia de un grupo humano, que refuerzan emocionalmente su sentido de comunidad con una identidad propia y que son percibidos por otros como característicos. El Patrimonio Cultural como producto de la creatividad humana, se hereda, se transmite, se modifica y optimiza de individuo a individuo y de generación a generación.

El Patrimonio Cultural-Natural parte de una visión donde la aproximación al patrimonio se redimensiona, no desde dos ópticas separadas, sino, por el contrario, entendiéndolo como un patrimonio integral que en América Latina es un continuo inseparable, como tal, es expresión de una intensa y permanente relación de los seres humanos y su medio. El Patrimonio Cultural-Natural está constituido por elementos de la naturaleza, que se mantienen en su contexto original, intervenidos de algún modo por los seres humanos. Como ejemplo, tenemos: vestigios arqueológicos o históricos, en su contexto natural original; vestigios fósiles paleontológicos asociados a actividad humana in situ; vestigios subacuáticos de actividad humana, y el Paisaje Cultural, producido en un determinado tiempo y espacio, que se ha mantenido inalterable.

El Patrimonio Tangible está constituido por objetos que tienen sustancia física y pueden ser conservados y restaurados por algún tipo de intervención; son aquellas manifestaciones sustentadas por elementos materiales productos de la arquitectura, el urbanismo, la arqueología, la artesanía, entre otros. El patrimonio tangible se subdivide en bienes inmuebles y bienes muebles.

El Patrimonio Intangible puede ser definido como el conjunto de elementos sin sustancia física, o formas de conducta que procede de una cultura tradicional, popular o indígena. Son las manifestaciones no materiales que emanan de una cultura en forma de saberes (conocimientos y modos de hacer enraizados en la vida cotidiana de las comunidades), celebraciones (rituales, festividades, y prácticas de la vida social), formas de expresión (manifestaciones literarias, musicales, plásticas, escénicas, lúdicas, entre otras) y lugares (mercados, ferias, santuarios, plazas y demás espacios donde tie- 
nen lugar prácticas culturales). El patrimonio intangible se transmite oralmente o mediante gestos y se modifica con el transcurso del tiempo a través de un proceso de recreación colectiva.

Es necesario evitar una polarización o dicotomía conceptual entre el patrimonio tangible e intangible, uno no es más importante que otro y ambas nociones deben ser concebidas como complementarias, pues aluden a dos dimensiones de una misma realidad.

I Diversos usuarios: al posibilitar el ingreso y la extracción de información por parte de diversos usuarios.

Todos los inventarios tienen dos tipos de usuarios, los internos a la institución patrimonial, y los usuarios externos, tradicionalmente, se limita a los especialistas / investigadores que utilizan la base de datos - previa autorización- para su trabajo profesional.

Si los miembros de la comunidad deben participar activamente en la detección de información sobre los bienes culturales de su comunidad, entonces, debemos aceptar que tienen el derecho de hacer uso, para su beneficio, de los instrumentos y herramientas desarrollados por las instituciones para preservar y difundir dichos bienes. Para que esto sea posible un requisito principal, es que, la información disponible para ser usada por los "actores locales" debe ser comprensible y utilizable por parte de éstos, y por lo tanto accesible por medio de un lenguaje no-técnico, abriendo la posibilidad que ésta sirva a una variedad de usuarios y a diversos fines:

- Al sector educativo - maestros y estudiantes- para utilizarlo como material

- Al público general para consultas

- A miembros de la localidad para el emprendimiento de iniciativas comunales o privadas (por ej. servicios y productos turísticos, rutas históricas, visitas guiadas, entre otras.)

- A entidades independientes de ocio/ turismo / negocio que quieren incorporar la localidad -y sus recursos patrimoniales- en sus ofertas existentes.

\section{EL MUSEO Y LA COMUNIDAD COMO ALIADOS Y SOCIOS}

El proceso de poner en valor un bien cultural -y principalmente que vuelva a tener una función social- es el modo más efectivo de preservarlo; en términos generales este proceso consiste en las siguientes acciones:

- en la detección de un bien(es) cultural(es) en peligro

- en su registro y documentación

- en su investigación (científica y participativa)

- en su intervención (acciones de conservación o restauración)

- en su difusión y acciones de concientización en la población

- en la puesta en función social de los habitantes (dependiendo del bien de que se trate, esto abre diversas posibilidades) 
A su vez, este proceso implica una transformación que lleva a convertir un bien patrimonial en un recurso patrimonial sobre el cual se puede generar un servicio o producto cultural. Como explica Jordi Juan-Tresseras (2003), el producto cultural es resultado final de un proceso de puesta en valor del recurso patrimonial (cultural, natural, tangible e intangible), el cual pasa por diversas fases: de identificación, conceptualización, creación y gestión del producto cultural. Por lo tanto, el producto cultural es el recurso patrimonial, sobre el que se puede realizar una actividad (visitar, asistir, participar, estudiar, comprar, comer,...) porque está formulada una propuesta de accesibilidad al mismo (cultural, temporal, espacial y económica) por parte del público. Cuando el producto cultural se promociona (se hace accesible al público) se convierte en oferta cultural, es decir que se realiza un programa con acciones de comunicación, generales o específicas, dirigidas a un público determinado (publicidad, folletos, libros, webs, catálogos,...). El público, atraído por el producto cultural promocionado, realiza el consumo cultural. Éste es la realización por parte del público de la/s actividad/es propuesta/s en el producto cultural. Los gestores turísticos (Vg. agencias) parten de la existencia de productos culturales para estructurar la oferta turística cultural a través de las redes de venta y/o de comunicación turística. Lo anterior podemos verlo gráficamente en el siguiente cuadro:

Gráfico 2. Proceso de transformación de un recurso patrimonial en una oferta cultural

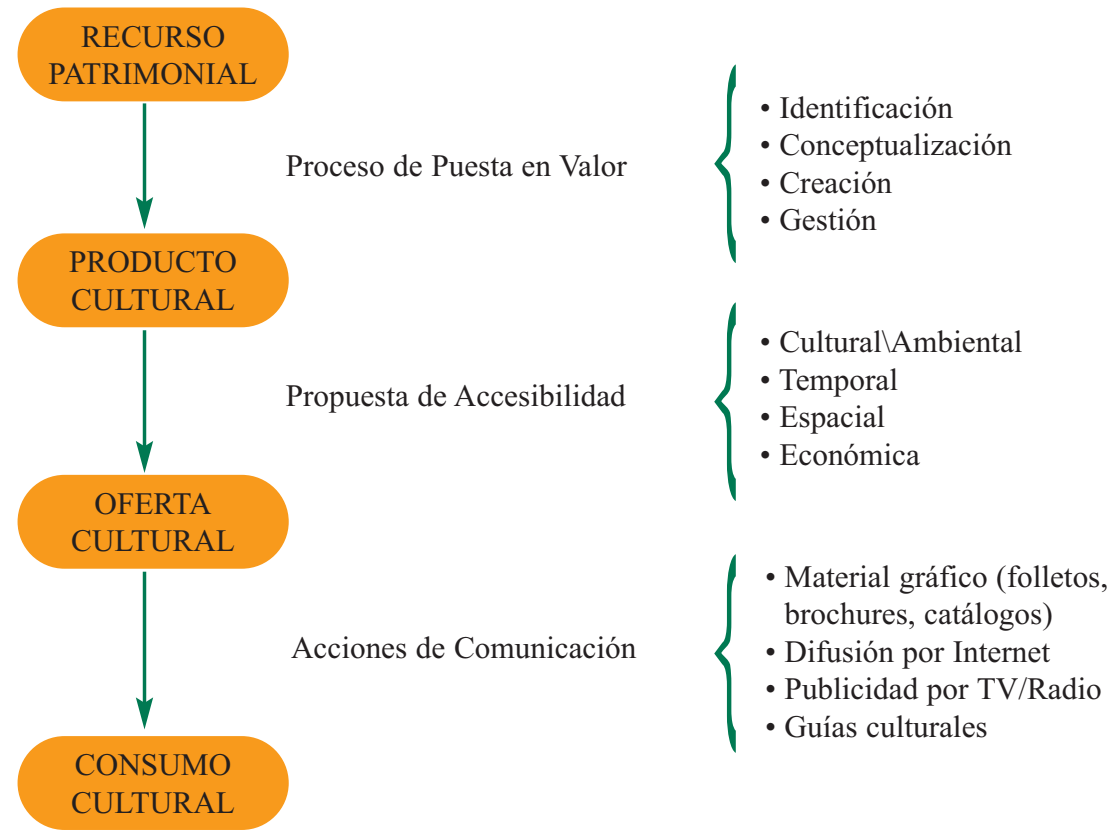


El museo y la comunidad en América Latina y el Caribe se encuentran hoy en día, en una situación de privilegio en cuanto a la posibilidad de responder a la demanda del turismo cultural y natural, por medio de la puesta en valor y oferta cultural de los recursos patrimoniales.

La visita al museo debe ser una experiencia integral que involucre todos los sentidos a través de atmósferas, narrativas, diseño de exhibiciones y escenografías para la ambientación de actividades relacionadas. (Bacci, 2000) Cada vez más el visitante nacional y extranjero busca experiencias de vida y que le cuenten historias que le permitan imaginar y vivir sensaciones.

Ha llegado el momento de establecer un vivo y fructífero contacto con el visitante, no únicamente para conocerlo y darle satisfacción a su demanda específica, como en un mercado para el consumo, sino para abrirle nuevas perspectivas dialogales. Ofrecerle espacios - dentro y fuera del museo- donde pueda establecer un diálogo afectivo y significativo con el (o su) patrimonio y con la historia, como individuo y como ser social.

Pero, ¿cómo puede el museo establecer este diálogo?, ¿cómo crear las conexiones entre los objetos o los sitios históricos y los visitantes? Podemos contextualizar los objetos (de hecho lo estamos haciendo), pero difícilmente podríamos darles vida nuevamente para integrarlos en una propuesta museológica que permita al visitante una experiencia transformadora.

Debemos buscar un "nexo vital" que nos posibilite establecer este diálogo afectivo y significativo. Consideramos que esto es posible en la medida que -en el desarrollo de estas "experiencias"- la comunicación entre el museo y el público no se realice exclusivamente a través de los especialistas, intérpretes o actores contratados, sino que se integre a personas (de la comunidad) que posean una relación directa con la temática del museo y su contexto patrimonial.

Estos individuos o grupo de personas deben poseer "información" relacionada con la temática del museo. Esta puede ser de varios tipos: información histórica / anecdótica de determinados hechos, personajes o lugares, sobre "conocimientos" producto del saber popular o científico, o sobre técnicas y oficios tradicionales, entre otras. Pueden ser personas que trabajaron en el lugar (en el edificio histórico o en el espacio patrimonial) donde ahora está el museo o descendientes de las personas que produjeron o crearon los bienes patrimoniales que el museo preserva. Las posibilidades pueden ser muchas.

La originalidad de la propuesta reside en trabajar no sólo con objetos "auténticos", sino con personas "auténticas" en el sentido anteriormente señalado; así el museo logra constituirse y proyectarse como una institución que da respuesta a las necesidades del visitante nacional o extranjero, al producir en él un mayor impacto y significativas experiencias potenciando la singularidad y "autenticidad" de su propuesta.

$\mathrm{Si}$ aceptamos que las comunidades, como creadoras y/o herederas de su patrimonio, deben ser aliadas en las actividades tendientes a su preservación y que poseen la experiencia y capacidad para hacerlo, entonces, podemos considerar a sectores o miem- 
bros de la comunidad no sólo como aliados estratégicos, sino también como socios potenciales en el desarrollo de actividades y proyectos conjuntos.

Respondiendo a su compromiso con el patrimonio y la comunidad, el museo debe establecer diversos formas de relaciones con la comunidad: como público privilegiado, como aliada y como socia del museo.

Gráfico 3. Diversas formas del Museo de relacionarse con la Comunidad

\section{LA COMUNIDAD}

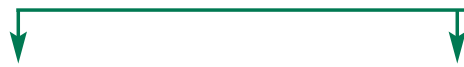

como

"público privilegiado"

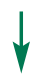

de las acciones de comunicación (educativas) del Museo como

«aliada»

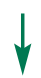

en la preservación y puesta en valor de los recursos patrimoniales

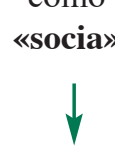

en la creación de productos y/o servicios culturales y su oferta al público

Bajo estas relaciones, el museo propone específicamente a sectores o miembros de la comunidad (de alguna manera relacionados con la temática del museo) establecer una alianza estratégica para incidir positivamente en la preservación del patrimonio y con el propósito de desarrollar en forma conjunta, con el personal del museo, actividades y proyectos productivos para la creación de una oferta novedosa y diversificada que presentarán al público y al turismo.

Con base en el entendimiento de las necesidades individuales y colectivas, nos proponemos darle prioridad a las iniciativas de trabajo que generan beneficios tangibles para la comunidad; esto como la base sobre la cual establecer una nueva relación.

Esta nueva relación consiste en encontrar las vías y establecer las estrategias por las cuales el museo pueda tener un impacto directo en la vida cotidiana de la comunidad, creando el interés de ésta en llevar a cabo actividades que involucren la puesta en valor y el usufructo de su patrimonio sobre la base de una responsabilidad compartida.

Lo importante para la propuesta es generar beneficios a los miembros de las comunidades; que los individuos involucrados - como aliados o como socios- perciben entonces una ganancia económica no por recibir un salario del museo, sino por medio del desarrollo de una actividad de carácter privado, bajo su propia responsabilidad. Los beneficios de cada individuo variarán según su interés de participar, su necesidad y capacidad. 


\section{EL MUSEO DE CULTURA POPULAR DE COSTA RICA: UN CASO DE ESTUDIO}

A fin de comprender mejor la propuesta de trabajo entre un museo y la comunidad para la oferta conjunta de servicio y/o productos culturales al visitante nacional y turista extranjero, presento el caso del Museo de Cultura Popular, cuyo proyecto y equipo interdisciplinario, responsable del desarrollo de las estrategias y herramientas propuestas, coordiné desde su inicio hasta su apertura al público en 1994.

El Museo de Cultura Popular con sede en Santa Lucía de Heredia, Costa Rica, inició a mediados de los años ochenta como un proyecto de extensión e investigación de la Universidad Nacional buscando una respuesta a la necesidad existente en el país de disponer de una institución que coadyuvara en la conservación, difusión y reactivación de los conocimientos y prácticas tradicionales de la región cultural del Valle Central de Costa Rica.

En la provincia de Heredia se ubican los cantones de Barva y San Rafael, en el entrecruce de estos cantones se encuentra el Museo de Cultura Popular. Las comunidades de Barva y San Rafael son herederas de una gran riqueza cultural, pero en los últimos cincuenta años el escenario de estas localidades, otrora agrícolas y artesanales, ha cambiado drásticamente, dándose un proceso de desestructuración social y falta de valorización hacia el patrimonio cultural y natural que les proporcionaron su particular modo de ser. Sin embargo, aún hoy es común observar como luchan por mantenerse algunas prácticas culturales propias del lugar y como importantes recursos patrimoniales no son tomados en cuenta para ser utilizados como potenciales generadores de ingresos, que posibiliten un mejoramiento en la calidad de vida de estas comunidades.

Por medio de su propuesta metodológica el Museo de Cultura Popular buscó ser un ente dinamizador para que las comunidades reconozcan su potencial cultural y sus habilidades para usar su patrimonio como fuente de desarrollo local.

El Museo de Cultura Popular no se distingue a primera vista de otro museo local o regional; cuenta con un área de $3000 \mathrm{~m}^{2}$ y dispone de un espacio para la exhibición permanente, un salón multiuso, oficinas y taller, un restaurante y áreas verdes. La exposición permanente consiste en la ambientación de una casa histórica, representativa de la arquitectura tradicional del siglo XIX, construida con la técnica tradicional de bahareque (construcción de caña y barro). La ambientación histórica de la casa muestra una colección de mobiliario, utensilios, herramientas y objetos de uso cotidiano que nos permiten visualizar contextos y prácticas cotidianas de mujeres, niños y hombres propios de las familias costarricenses de fines del siglo XIX e inicios del siglo XX. La exposición permanente, como el entorno natural con plantas medicinales y árboles frutales, es un referente importante que sirve de preámbulo para la implementación de otras exposiciones temporales y de actividades diversas de investigación y difusión: visitas guiadas, charlas, talleres, celebración de actividades festivas tradicionales y actividades lúdicas.

Lo que le distingue, es que se propuso desarrollar las funciones museológicas de preservación, investigación y comunicación, incorporando la identificación y el apoyo a los cultores populares, "aquellas personas, reconocidas como miembros de la comunidad, que 
poseen y manejan ciertos conocimientos empíricos tradicionales, plasmándolos y/o transmitiéndolos a través de una práctica creadora concreta" (DeCarli, 2007) proponiendo la generación de recursos para el museo y de beneficios a la comunidad, por medio del desarrollo de actividades de reactivación productiva de las prácticas y oficios tradicionales.

Foto 1. Imágenes del desplegable del Museo de Cultura Popular, Costa Rica.

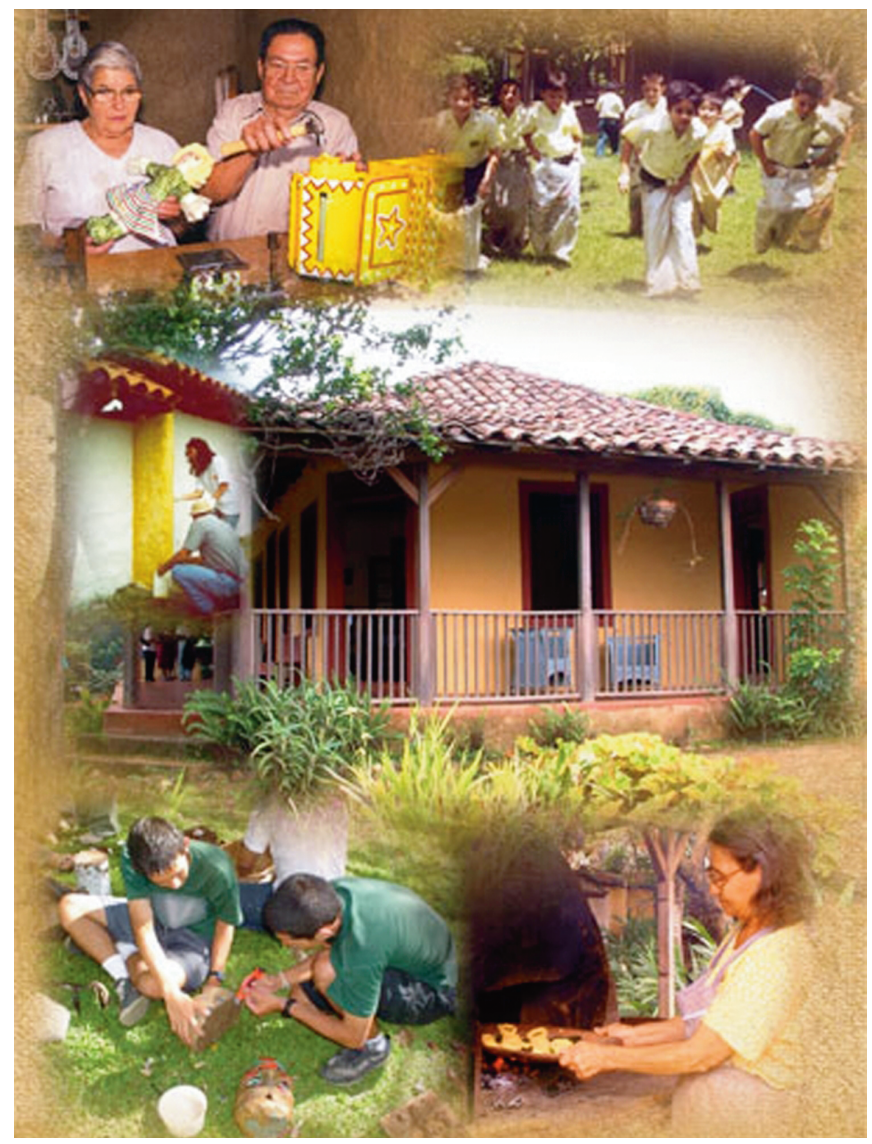

El Museo conjuntamente con miembros de las comunidades organizados en proyectos productivos sobre gastronomía tradicional costarricense, construcción tradicional en bahareque, elaboración de máscaras tradicionales, confección de juguetes tradicionales y producción de plantas medicinales, ofrecen a los visitantes nacionales y turistas, productos y servicios de alta calidad, poniendo en valor su patrimonio y generando beneficios en las comunidades aledañas.

Para la puesta en marcha de cada proyecto productivo se parte de los siguientes objetivos:

1. Investigar las temáticas del futuro proyecto productivo y rescatar información sobre las prácticas culturales asociadas para generar el contenido creativo de los 
productos y servicios que se ofrecerán, con el propósito de dar a conocer y revitalizar las tradiciones culturales de la región.

2. Seleccionar, organizar y capacitar en gestión empresarial y cultural a los miembros de las comunidades (con los conocimientos y habilidades necesarios) para integrar el proyecto productivo con el fin de que participen en la oferta cultural del Museo.

3. Generar las condiciones técnicas, de accesibilidad y de infraestructura en el Museo que posibiliten el buen funcionamiento del proyecto productivo y una oferta de productos y servicios de calidad.

4. Establecer los mecanismos pertinentes para el mercadeo y comercialización de los productos y servicios que se ofrecen conjuntamente en el Museo y fuera de él, permitiendo así la sostenibilidad y fortalecimiento del proyecto productivo, así como la generación de recursos para el museo.

La estrategia principal es por medio de la organización de talleres interactivos de reactivación de prácticas tradicionales, donde se trasmiten de una manera amena los conocimientos, impartidos por los propios cultores populares, estableciéndose así un verdadero "nexo vital" en el cual los visitantes - nacionales y extranjeros- participan de una experiencia afectiva y significativa relacionadas con el patrimonio cultural tangible e intangible de la localidad.

A modo de ejemplo, veamos la propuesta del Museo para los estudiantes extranjeros (sector del turismo cultural) que se encuentran aprendiendo el idioma español, los cuales encuentran en el museo un ambiente propicio para el aprendizaje de la lengua por medio de:

I Visitas acompañadas por el guía del museo en la casona y su entorno natural, donde se conversa sobre arquitectura vernácula, tradición oral, gastronomía tradicional, plantas medicinales, los modos de vida del costarricense en estrecha relación con la naturaleza y el conocimiento de ella dentro de una cultura agrícola.

I Oferta de servicio de comidas y bebidas tradicionales en el restaurante "La Fonda" con una opción de menú para refrigerios, almuerzos y cenas durante toda la semana, previa reservación y durante los domingos abierto sin reservación.

I Participación en juegos tradicionales como andar en zancos, bailar trompos, etc. En la tienda pueden adquirir los juguetes tradicionales como otros productos elaborados por cultores populares: máscaras tradicionales, productos gastronómicos, plantas medicinales; así como publicaciones y ediciones audio-visuales relacionadas con las temáticas del Museo.

I Participación en los talleres de prácticas tradicionales; entre estos, el taller Aprender haciendo: la cocina tradicional costarricense impartido por las señoras integrantes del proyecto productivo "Reactivación de la cocina tradicional" es uno de los más solicitados por los visitantes extranjeros. Estos pueden seleccionar entre elaborar recetas utilizando el horno de barro (pan casero de trigo, pan de yuca o bizcochos de maíz); o utilizando la cocina de leña (prestiños con miel 
de caña o tortillas de maíz). Al finalizar los participantes degustan sus creaciones culinarias acompañados con autenticas bebidas tradicionales como café, agua dulce o frescos de frutas de estación.

De esta forma, en el Museo de Cultura Popular de Costa Rica, el turista cultural tiene la posibilidad única de interactuar con los cultores populares y conocer sobre la cultura local directamente desde su experiencia, por medio de su participación en los talleres interactivos.

\section{A MODO DE CONCLUSIÓN}

Para el éxito de la propuesta, es indispensable que el museo y un grupo organizado de la comunidad actúe como socios en el proceso de creación de servicios y productos culturales y su oferta al público. Lo anterior le permite al museo ampliar las bases para una oferta diversificada que se destaca por su singularidad y autenticidad, y a las comunidades generar sus propios recursos utilizando formas sostenibles de uso del patrimonio.

Desde luego el museo debe tener en claro dos situaciones que se derivan de la propuesta de crear servicios y/o productos culturales en conjunto con sectores de la comunidad:

- Primero, que el proceso de puesta en valor de un recurso patrimonial para la creación de ofertas culturales debe ser resultado de un serio y meticuloso proceso de investigación y de responsabilidad compartida con el grupo de la comunidad en el manejo y uso de este recurso patrimonial.

- Segundo, que en el desarrollo de creación de productos culturales y su oferta al público debe monitorearse permanentemente el impacto, directo e indirecto que este puede producir en la comunidad, y tomar las medidas preventivas para contrarrestar toda posible consecuencia negativa.

La mayor parte de proyectos exitosos provienen de la oferta al sector turístico, en estos proyectos se evidencia claramente los beneficios de una alianza entre el museo y su comunidad y su oferta conjunta diseñada para el turismo cultural. Sin embargo, el museo y la comunidad deben tener siempre muy claras sus prioridades en relación a los recursos patrimoniales que preservan, ya que como bien lo señala Ramón Bonfil (2003) "tales patrimonios tienen en primer lugar, el valor de documentos del transcurrir del hombre y la sociedad a través de la historia y factor de identidad y cohesión social del grupo que lo genera, y que su valor en tanto que atractivo turístico generador de riqueza, si bien es innegable e importante en el actual momento, es un valor agregado que nunca debe sustituir la primacía del primero".

\section{BIBLIOGRAFÍA}

Bacci, María Eugenia (2000): Museos: ¿Por qué invertir en ellos? El papel de los museos en el desarrollo económico y social de la comunidad, Estudio realizado por la Fundación Aragua, Caracas, Venezuela. Julio, 2000. 
Bonfíl Castro, Ramón (2003): Patrimonio Cultural, Desarrollo y Turismo ponencia presentada en su calidad de Presidente del ICOMOS Mexicano en el Congreso Iberoamericano de Patrimonio Cultural, Desarrollo y Turismo. Morelia, Michoacán, México. Junio, 2003.

DeCarli, Georgina (2007): Un Museo Sostenible: museo y comunidad en la preservación activa de su patrimonio, UNESCO, San José, Costa Rica.

DeCarli, Georgina y Tsagaraki, Christina (2006): Un Inventario de Bienes Culturales: porqué y para quién. Publicación electrónica, www.ilam.org, 2006.

ICOM (2000): "Propuesta del ICOM para una Carta de Principios sobre Museos y Turismo Cultural. Esta propuesta fue elaborada por los participantes en el taller "Museos, Patrimonio y Turismo Cultural" organizado por el ICOM, con la colaboración de los comités nacionales peruano y boliviano, en Trujillo (Perú) y La Paz (Bolivia), del 21 al 27 de mayo de 2000.

Juan-Tresserras, Jordi (2003): El aprovechamiento turístico de los bienes patrimoniales. Ponencia presentada en el Congreso Iberoamericano: Patrimonio Cultural, Desarrollo y Turismo, Morelia, México, Junio del 2003.

Lacouture F., Felipe (1994): “Museo, Política y Desarrollo en visión retrospectiva y presente: México y América Latina”, En: Antología del Cuarto Curso Interamericano de Capacitación Museográfica, Escuela Nacional de Conservación, Restauración y Museografía, INAH, México, Octubre, 1994. 